Southern Illinois University Carbondale

OpenSIUC

Publications

Department of Zoology

9-2009

\title{
Ontogenetic Patterns of Agonistic Behavior in a Guild of Larval Ambystomatid Salamanders
}

CyL. Mott

Southern Illinois University Carbondale

Donald W. Sparling

Southern Illinois University Carbondale

Follow this and additional works at: http://opensiuc.lib.siu.edu/zool_pubs

Published in Journal of Herpetology, Vol. 43 No. 3 (September 2009) at http://dx.doi.org/10.1670/

07-236R.1

\section{Recommended Citation}

Mott, Cy L. and Sparling, Donald W. "Ontogenetic Patterns of Agonistic Behavior in a Guild of Larval Ambystomatid Salamanders." (Sep 2009).

This Article is brought to you for free and open access by the Department of Zoology at OpenSIUC. It has been accepted for inclusion in Publications by an authorized administrator of OpenSIUC. For more information, please contact opensiuc@lib.siu.edu. 


\title{
Ontogenetic Patterns of Agonistic Behavior in a Guild of Larval Ambystomatid Salamanders
}

\author{
Cy L. Mott ${ }^{1}$ and Donald W. Sparling \\ Cooperative Wildlife Research Laboratory and Department of Zoology, Southern Illinois University, \\ Carbondale, Illinois 62901 USA
}

\begin{abstract}
Aвstract.-Agonistic behavior is a common feature of larval amphibians inhabiting temporary ponds. Given the temporally staggered sequence of hatching by pond-breeding amphibians, ontogenetic patterns of aggression can influence coexistence if larvae of certain species or ages are subject to increased aggression. To determine whether aggression changes through larval ontogeny, we observed agonistic behavior of Ambystoma opacum, Ambystoma tigrinum, and Ambystoma maculatum at four stages of development spanning the larval period. We tracked aggression rates among individual larvae to determine whether previous success, in the form of increased aggression, facilitated success in subsequent contests. All species exhibited distinct ontogenetic patterns of aggression, with the highest and lowest rates of aggression exhibited during rear leg development and metamorphosis, respectively. Species-specific aggression rates were observed, with $A$. tigrinum consistently displaying the highest levels of aggression. Winner or loser effects were not evident, because increased aggression early in the larval period did not result in increased aggression throughout ontogeny. We hypothesize that the observed patterns of behavior may represent a baseline level of aggression upon which other biotic and abiotic factors act in mediating coexistence among larval amphibians.
\end{abstract}

Larval ambystomatid salamanders inhabiting temporary ponds experience dramatic seasonal and annual fluctuations in larval density, refugia abundance, and food availability, all of which influence the prevalence of agonistic behaviors (Stenhouse, 1985; Walls, 1995; Wildy et al., 2001). Seasonal changes in aggression also may be attributed to temporally staggered patterns in which species emerge in ponds, because it contributes to inter- and intraspecific size variation that promotes cannibalism and predation (Stenhouse et al., 1983; Smith, 1990). Early hatching species prey on both smaller conspecifics and later-emerging heterospecific larvae, to such an extent that populations of late-hatching species may be considerably reduced or extirpated (Walls and Williams, 2001; Boone et al., 2002). Larval ambystomatid salamanders also exhibit guild structure, because potential intra- and interspecific competitors may consume one another in addition to shared prey. Therefore, seasonal changes in species composition influence the interplay between intraguild aggression among salamander larvae and strict predator-prey interactions between larvae and shared prey items, such as tadpoles (sensu Polis et al., 1989).

Temporal variation in larval aggression has been examined in the context of environmental changes occurring within ponds (Semlitsch and Reichling, 1989; Sredl and Collins, 1992; Bridg-

\footnotetext{
${ }^{1}$ Corresponding Author. E-mail: cm8755@siu.edu
}

es, 1999). However, less frequently observed are changes occurring within individual larvae, with the most notable example being the shift in diet and behavior associated with the development of the cannibal phenotype in Ambystoma tigrinum (Powers, 1907; Reilly et al., 1992). Although most Ambystoma species do not develop cannibal phenotypes, larvae may still exhibit variable levels of aggression through ontogeny. Behavioral variation may arise from the dramatic changes in morphology and mode of locomotion occurring during the larval period (Hassinger et al., 1970), and Ambystoma larvae exhibit ontogenetic shifts in other behaviors associated with aggression and feeding, such as kin recognition (Blaustein and $\mathrm{O}^{\prime}$ Hara, 1986), predator avoidance (Mathis et al., 2003), and prey selection (Leff and Bachmann, 1986).

Temporal variation in larval aggression may also arise from winner or loser effects, in which success or failure during one encounter influences the outcome of subsequent encounters (Landau, 1951a,b). Because larval Ambystoma repeatedly interact aggressively through ontogeny (pers. obs.), a population of larvae exhibiting winner or loser effects may segregate over time into aggressive (winner) larvae and submissive (loser) larvae. Winning, or in this case, simply being more aggressive, would likely confer advantages over losers that include relatively increased growth (Brodman, 2004) and decreased risk of reciprocal aggression (Walls and Semlitsch, 1991).

Ontogenetic changes in aggression have previously been shown to influence competitive 
interactions and associated mortality among aquatic invertebrates (Wissinger, 1989), and if larval salamanders exhibit similar ontogenetic behavioral patterns, survival would be influenced in multiple ways. First, ontogenetic behavior patterns could act as a "baseline" upon which other factors, such as larval density and refugia abundance, would act in either synergistic or antagonistic fashion to affect survival. Second, the timing in peaks of aggression among larvae could identify the species and seasons exhibiting the most intense levels of aggression, because species emerge at different times of the year and, therefore, are at varying stages of development during coexistence (sensu Hansson et al., 2007). Third, the presence of ontogenetic patterns of aggression could influence seasonal changes in other factors associated with injury and survival among larval amphibians, such as proliferation of fungal infections on wounds (Walls and Jaeger, 1987), variation in population size structure, and relative growth rates (Brunkow and Collins, 1996).

In determining whether larval salamanders exhibit ontogenetic patterns of aggression, we designed a laboratory experiment in which rates of larval aggression were recorded throughout the larval period for individual larvae. Given that multiple species of Ambystoma typically cohabit in ponds, we also sought to determine whether aggression levels change through time among multiple species in similar fashion. Because larval density significantly affects aggressive interactions (Walls, 1998), we hypothesized that one mechanism through which aggressive encounters are mediated is spatial partitioning among larvae; therefore, we recorded distances separating larvae during behavioral trials to identify relationships between partitioning and aggression. Finally, we examined how aggressive behaviors that larvae either performed or were subjected to at a given developmental stage influenced aggression in subsequent developmental stages through the presence or absence of winner and loser effects.

\section{Materials And Methods}

Animals and Rearing Conditions.-Temporary ponds typically contain a mixture of larvae from fall- and spring-breeding species; therefore, we used Ambystoma opacum, A. tigrinum, and Ambystoma maculatum as focal species. In Illinois, A. opacum larvae typically hatch between November and December, whereas A. tigrinum and $A$. maculatum hatch between February and March (pers. obs.) The larval periods of these species overlap considerably, with $A$. opacum, $A$. maculatum, and A. tigrinum metamorphosing predominantly in May, July, and June, respec- tively (Regester et al., 2006). Although A. opacum exhibits a considerable size advantage over later-breeding species for a majority of the larval period, A. tigrinum exhibit faster growth rates (Keen et al., 1984) and larger maximum lengths than other Ambystoma species and often prey on A. maculatum larvae (Petranka, 1998). Therefore, given the differential growth rates and temporal overlap among these species, ontogenetic patterns of aggression could be of great importance in these communities.

In January 2006, about one-month-old A. opacum larvae were collected from ephemeral ponds in the Shawnee National Forest (SNF) and Touch of Nature Environmental Center (TONEC) of southern Illinois. Larvae were transported to the laboratory and housed individually in $15 \times 12 \times 5 \mathrm{~cm}$ containers filled with $600 \mathrm{~mL}$ of reconstituted water (Horne and Dunson, 1995). Larvae were reared under a 12 : $12 \mathrm{~L}$ : D photoperiod and a temperature ranging between $15^{\circ} \mathrm{C}$ and $21^{\circ} \mathrm{C}$. Larvae were maintained on a daily diet consisting of the amount of Artemia sp. nauplii hatching from $0.015 \mathrm{~g}$ of eggs, and larvae received fresh reconstituted water every 5-8 days.

In April 2006, 10 egg masses each of $A$. tigrinum and A. maculatum were collected from ephemeral ponds in SNF and TONEC. We collected egg masses instead of recently-hatched larvae of these species because of the relatively low abundance of $A$. tigrinum in southern Illinois (Regester et al., 2006) and the prevalence of lethal fungal infections in A. tigrinum and $A$. maculatum egg masses that prevented hatching in situ (pers. obs.)

Egg masses were housed individually in $15 \times$ $12 \times 5 \mathrm{~cm}$ containers filled with $600 \mathrm{~mL}$ of reconstituted water (Horne and Dunson, 1995) until hatching. To allow larvae to recognize and interact with conspecifics prior to behavioral trials, hatchling larvae from 3-4 egg masses were transferred into $35 \times 25 \times 11 \mathrm{~cm}$ containers filled with 9 liters of reconstituted water and allowed to cohabit for a period of 30 days at densities equivalent to $A$. opacum collected from ponds (CLM, unpubl. data.). During this period, larvae were housed under the same photoperiod, temperature, and feeding regime as A. opacum, and were provided with refugia in the form of approximately 20 Acer spp. leaves to minimize cannibalism prior to behavioral trials. After 30 days, larvae were transferred to individual $15 \times$ $12 \times 5 \mathrm{~cm}$ containers and reared in the same manner as A. opacum.

Experimental Apparatus and Procedure.-Prior to behavioral observations, larval head width (HW), snout-vent length (SVL), and total length (TL) were determined from digital photographs 
using ImageJ image analysis software (Abramoff et al., 2004). Larvae were then assigned to intraspecific pairs based on equal HW, although they remained in individual containers prior to behavioral trials. Once larvae were measured and paired, they received fresh reconstituted water and were fasted for $24 \mathrm{~h}$ to standardize hunger levels.

A circular arena (diameter $=19 \mathrm{~cm}$, water depth $=3.5 \mathrm{~cm}$ ) was used to observe aggression among intraspecific larval pairs of each species. The arena was surrounded by opaque material on all sides to prevent the interference of outside stimuli during behavioral trials, and behavioral trials were conducted during the "dark" portion of the photoperiod because Ambystoma larvae are known to be more active at night (Branch and Altig, 1981). Behavioral observations were either viewed under flashlights equipped with red cellophane filters or video recorded under infrared lighting.

For each pair of larvae, individuals were placed separately into perforated cups within the arena for $5 \mathrm{~min}$. Perforations in cups allowed for exchange of water but prevented larvae from seeing or interacting with each other. Larvae were then released from their cups, and aggressive behaviors were recorded for $30 \mathrm{~min}$. To quantify larval aggression, the combined counts of the behaviors "move toward" (MT), "lunge" (LU), "bite" (BT), and "predation" (PRED) were recorded for one randomly selected larva in each trial; definitions of these behaviors follow Walls and Jaeger (1987). To distinguish the aggressive behavior MT from random movements within the arena that might result in one larva moving toward another, MT was defined as occurring when less than one body length separated larvae. We also recorded rates of "mutual approach" (MA), which consisted of both larvae simultaneously performing a "move toward" behavior. Distance between the heads of larvae in the arena (DIST) was recorded to the nearest centimeter every $5 \mathrm{~min}$ during trials to determine whether spatial partitioning varied with developmental stage, species, or the associated rates of aggressive behaviors.

To record aggression through larval ontogeny, we observed behaviors at four distinct developmental stages which encompassed the entire larval period. Larval developmental stages were defined as follows: (1) recently hatched: larvae that had not yet developed rear legs; (2) rear legs developed: larvae with recently ( $<1$ month prior to behavioral trials) developed rear legs; larvae at this stage possessed rear limbs that were shorter and thinner than the front limbs; (3) premetamorphic: larvae with fully developed rear legs ( $>1$ month since development of rear legs) but not yet metamorphosing; larvae at this stage possessed rear limbs that were longer and thicker than the front limbs; (4) metamorphic: larvae in the process of reabsorbing gills and tailfins.

Thirty trials were conducted for each species at each developmental stage, resulting in a total sample size of 360 intraspecific behavioral trials and individual observations. For trials at each developmental stage, larvae were measured, haphazardly assigned to pairs based on equal HW, and observed in the manner described above. After each trial at each developmental stage, larvae were returned to individual containers, immediately fed, and reared under the same conditions as prior to trials. During subsequent trials, larvae were never paired with the same individual from a previous trial.

Statistical Analyses.-All statistical analyses were conducted using SAS Version 9.1 (SAS Institute Inc., Cary, NC). Prior to all statistical analyses, one larva from each pairwise comparison was randomly selected as the focal individual, resulting in a sample size of 30 individuals for each species at each developmental stage. To test the null hypothesis that counts of aggressive behavior would remain unchanged over the course of the larval period among the three focal species, we used split-plot analysis of covariance to test the fixed effects of species (whole-plot effect) and developmental stage (split-plot effect) on aggressive behavior counts of focal individuals, with behavior counts of nonfocal individuals as a covariate. Following identification of an overall significant effect of species or developmental stage on aggression, we employed post hoc TukeyKramer tests to determine which species or developmental stages significantly differed from one another. To test the null hypothesis that space separating larvae during trials (partition distance) was not associated with changes in larval aggression, we conducted linear regression for each species using average distance separating larvae during trials and the average counts of aggressive behaviors from both larvae in each trial as independent and dependent variables, respectively.

To identify winner or loser effects among larvae, we conducted linear and quadratic regression analyses between an index value of the intensity of aggression experienced by a focal larva in a selected developmental stage and their aggression level in the subsequent developmental stage. As our index value, we used the formula [(AGG1/AGG2) $\times$ AGG1], where AGG1 and AGG2 represent the numbers of aggressive behaviors performed by the more and less aggressive larvae in a pair, respective- 
TABLE 1. Results of split-plot analysis of covariance for the effects of larval species and developmental stage on the aggressive behaviors "Move Toward," "Lunge," "Bite," "Predation," and "Mutual Approach" among larval Ambystoma opacum, Ambystoma tigrinum, and Ambystoma maculatum, with aggression of nonfocal larvae (competitor) as a covariate.

\begin{tabular}{lrrr}
\hline \hline \multicolumn{1}{c}{ Source } & DF & \multicolumn{1}{c}{$F$} & \multicolumn{1}{c}{$P$} \\
\hline Species & 2 & 14.76 & $<0.001$ \\
Competitor & 1 & 2.44 & 0.122 \\
Error A (Whole-plot effect) & 86 & & \\
Stage & 3 & 29.48 & $<0.001$ \\
Species $\times$ Stage & 6 & 5.90 & $<0.001$ \\
Competitor & 1 & 11.17 & 0.001 \\
Error B (fixed-plot effect) & 260 & & \\
Total (corrected) & 359 & & \\
\hline
\end{tabular}

ly. However, for trials where one larva failed to perform any aggressive behaviors (AGG2 $=0$; $N=91$ trials), this formula would be unsuitable as any AGG1/0 = undefined. Therefore, in these cases, we used the formula $\left(\mathrm{AGG1}^{2}+\right.$ AGG1) to calculate appropriate index values (e.g., A trial with AGG1 $=5$, AGG2 $=0$ should produce an index value between trials with AGG1 = 6, AGG2 $=1$ and AGG1 = 5, AGG2 = 1). Finally, a positive or negative sign was assigned to the index value based on whether the focal larva was the more or less aggressive larva of a pair, respectively. Following these procedures, a focal larva that was very aggres- sive to the nonfocal larva without reciprocal aggression would exhibit a high positive index value, whereas a focal larva that was not aggressive but experienced high levels of aggression from the nonfocal larva would exhibit a high negative value. Pairs that reciprocated aggression would exhibit intermediate index values that increased with increasing aggression. Overall, if unreciprocated aggression by the focal larvae resulted in increased aggression in the subsequent developmental stage (i.e., a winner effect was observed), a positive relationship between index values from one stage and subsequent aggression level in the next stage should be observed.

\section{Results}

Ontogenetic Effects.-Both among and within species, rates of larval aggression varied significantly with developmental stage (Table 1, Fig. 1). Post hoc Tukey-Kramer tests indicated that for all species combined, stage 2 larvae were significantly more aggressive than all other stages $(P<$ 0.001). Furthermore, stage 1 and 3 larvae were significantly more aggressive than stage 4 larvae $(P<0.001)$, but stages 1 and 3 did not differ significantly in aggression $(P=0.57)$. Aggression rates were highest among larvae with recently developed rear legs for A. opacum and A. tigrinum, and these rates were $150 \%$ and $129 \%$ higher than the next most aggressive developmental stage for each species, respectively. Ambystoma maculatum

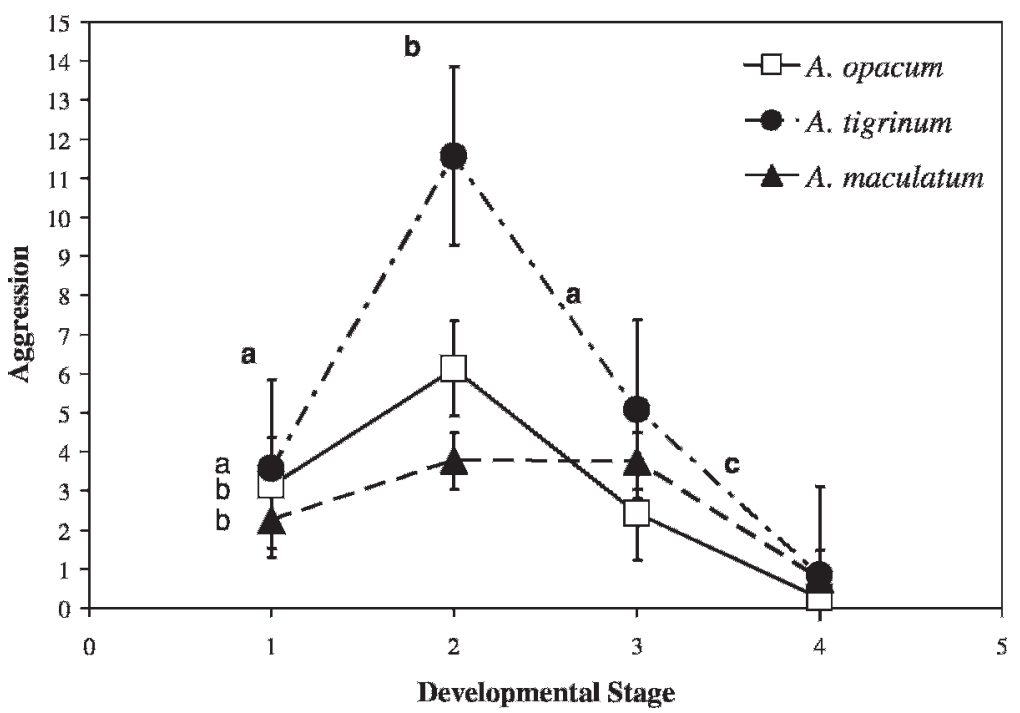

FIG. 1. Mean combined counts ( $\pm \mathrm{SE}$ ) of the aggressive behaviors "Move Toward," "Lunge," "Bite," "Predation," and "Mutual Approach" observed throughout the larval periods of Ambystoma opacum, Ambystoma tigrinum, and Ambystoma maculatum during 30-min observation periods. Letters above aggression rates at each developmental stage indicate stages which differ significantly from one another $(P<0.05)$, and letters to the left of stage 1 aggression values indicate species that differ significantly from one another $(P<0.05)$. 
TAble 2. Post hoc Tukey Kramer test results of all species-stage comparisons and their associated $P$-values from a split-plot analysis of covariance for larval aggression based on species and developmental stage. Species names are designated by initials $(\mathrm{O}=$ Ambystoma opacum, $\mathrm{T}=$ Ambystoma tigrinum, $\mathrm{M}=$ Ambystoma maculatum $)$, developmental stages are represented by values $1-4$, and $P<0.05$ are in bold.

\begin{tabular}{|c|c|c|c|c|c|c|c|c|c|c|c|}
\hline Stage & $\mathrm{O} 2$ & $\mathrm{O} 3$ & O4 & $\mathrm{T} 1$ & $\mathrm{~T} 2$ & T3 & $\mathrm{T} 4$ & M1 & M2 & M3 & M4 \\
\hline O1 & 0.088 & 0.998 & 0.014 & 1.000 & $<0.001$ & 0.236 & 0.059 & 1.000 & 1.000 & 1.000 & 0.062 \\
\hline $\mathrm{O} 2$ & & 0.004 & $<0.001$ & 0.171 & $<0.001$ & 1.000 & $<0.001$ & 0.018 & 0.168 & 0.163 & $<0.001$ \\
\hline O3 & & & 0.226 & 0.985 & $<0.001$ & 0.015 & 0.504 & 1.000 & 0.985 & 0.986 & 0.518 \\
\hline O4 & & & & 0.006 & $<0.001$ & $<0.001$ & 1.000 & 0.073 & 0.006 & 0.006 & 1.0000 \\
\hline T1 & & & & & $<0.001$ & 0.390 & 0.026 & 1.000 & 1.000 & 1.000 & 0.028 \\
\hline $\mathrm{T} 2$ & & & & & & $<0.001$ & $<0.001$ & $<0.001$ & $<0.001$ & $<0.001$ & $<0.001$ \\
\hline T3 & & & & & & & $<0.001$ & 0.064 & 0.386 & 0.377 & $<0.001$ \\
\hline $\mathrm{T} 4$ & & & & & & & & 0.222 & 0.028 & 0.028 & 1.000 \\
\hline M1 & & & & & & & & & 1.000 & 1.000 & 0.232 \\
\hline M2 & & & & & & & & & & 1.000 & 0.030 \\
\hline M3 & & & & & & & & & & & 1.000 \\
\hline
\end{tabular}

aggression was highest among premetamorphic larvae but only $8 \%$ higher than larvae with recently developed rear legs. For larvae of all species, metamorphosing individuals were the least aggressive, with aggression rates $71-88 \%$ lower than the next most aggressive stage for each species.

Species Effects.-At each developmental stage, significant differences in aggression were present among the three focal species (Table 1, Fig. 1). Post hoc Tukey-Kramer tests indicated A. tigrinum aggression throughout development was significantly higher than either $A$. opacum $(P<0.001)$ or $A$. maculatum $(P<0.001)$, but overall aggression did not differ significantly between $A$. opacum and $A$. maculatum $(P=0.70)$. Ambystoma tigrinum larvae were consistently the most aggressive species throughout ontogeny, with aggression rates $20-200 \%$ higher than $A$. opacum and 30-225\% higher than A. maculatum at the same developmental stage. During developmental stages 1 and 2, A. opacum exhibited 43-67\% higher aggression rates than A. maculatum, yet this pattern was reversed later in the larval period. During developmental stages 3 and 4, A. maculatum exhibited 62$100 \%$ higher aggression rates than $A$. opacum. In addition to overall differences in aggression by developmental stage and species presented above, individual comparisons of all speciesstage combinations and their associated $P$ values are provided (Table 2).

Spatial Partitioning.-Based on the results of linear regression, the distance separating larvae during trials was not significantly related to associated counts of aggressive behaviors among larvae for all species combined $\left(R^{2}<0.001, P=\right.$ $0.78)$. This lack of a pattern was also observed within species for $A$. opacum $\left(R^{2}=0.017, P=\right.$
$0.15)$, A. tigrinum $\left(R^{2}=0.004, P=0.47\right)$ and $A$. maculatum $\left(R^{2}=0.002, P=0.63\right.$; Fig. 2$)$.

Winner/Loser Effects.-After all ties had been eliminated, 105, 102, and 102 behavioral trials were used in identifying winner or loser effects among A. opacum, A. tigrinum, and A. maculatum, respectively. Previous experiences, as defined by index values of aggression, were not significantly related to the intensity of larval aggression displayed in subsequent developmental stages as determined by either linear $\left(R^{2}\right.$ $=0.002, P=0.40)$ or quadratic regression $\left(R^{2}<\right.$ $0.001, P=0.60)$, and the lack of relationship was observed both within and among species and developmental stages using either linear or quadratic regression (All $R^{2}<0.064, P=$ 0.095). However, the maximum aggression levels over the range of index values occurred for those larvae that experienced or performed very few aggressive behaviors in their previous developmental stage (Fig. 3).

\section{DISCUSSION}

The results of this study demonstrate that aggression is variable in a similar pattern through ontogeny among larval $A$. opacum, $A$. tigrinum, and A. maculatum, and species-specific rates of aggression at each developmental stage were also evident. In addition, larval aggression did not appear to be mediated by either winner or loser effects or spatial partitioning among larvae during trials.

Previous studies have shown that relative size and timing of hatching among Ambystoma larvae are important influences on larval aggression (Stenhouse, 1985; Brunkow and Collins, 1996; Boone et al., 2002). The results of our study suggest that larvae do not simply become 


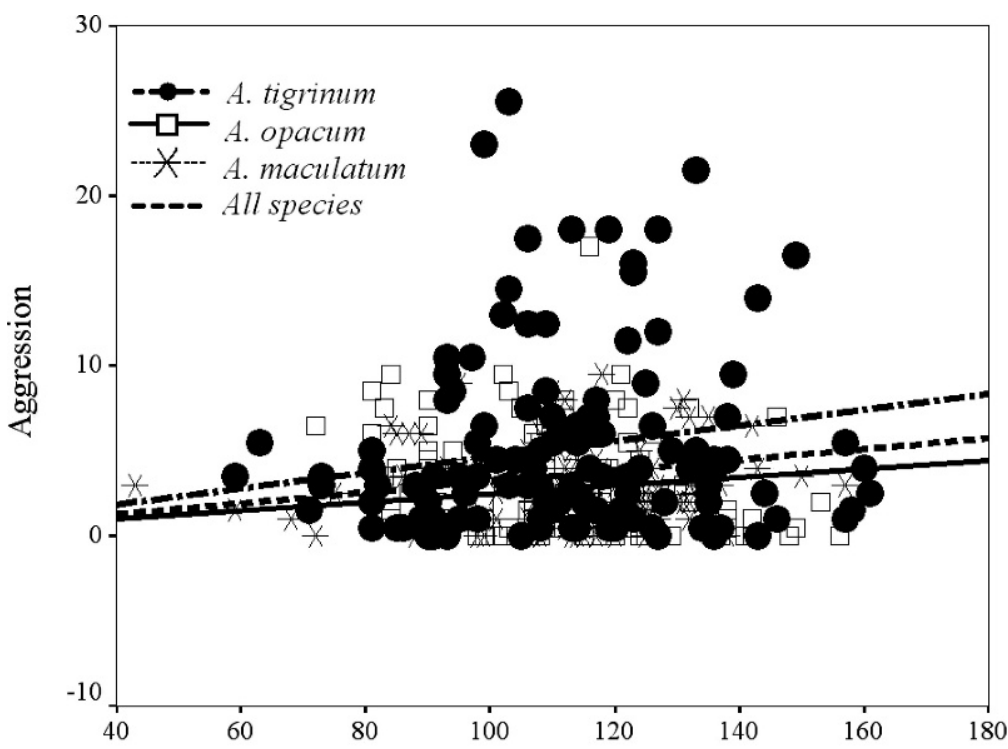

Distance

FIG. 2. Average distance $(\mathrm{cm})$ separating larval pairs during individual trials and the associated total counts of the aggressive behaviors "Move Toward," "Lunge," "Bite," "Predation," and "Mutual Approach" from 30min observations of Ambystoma opacum, Ambystoma tigrinum, and Ambystoma maculatum among all developmental stages. The regression line for A. maculatum lies directly behind that of $A$. opacum.

more aggressive as they grow larger. As a result, timing of hatching may impact aggression by influencing which species are present when a focal species reaches its most aggressive developmental stages, not necessarily its largest size. For example, larvae of fall-breeding $A$. opacum initially possess a considerable size advantage over larvae of spring-breeding $A$. tigrinum and $A$. maculatum (pers. obs.). However, because of the predicted decreases in $A$. opacum aggression at the time of $A$. tigrinum and A. maculatum emergence (Fig. 4), predation by

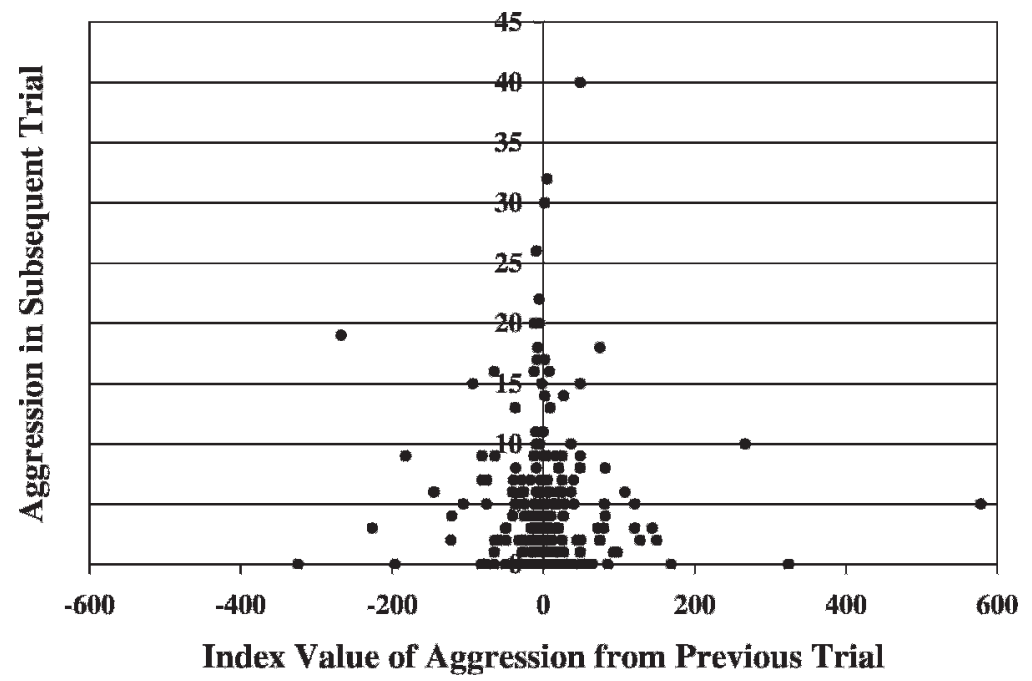

FIG. 3. Relationship of the index value of aggression for a selected developmental stage and the combined totals of the aggressive behaviors "Move Toward," "Lunge," "Bite," "Predation," and "Mutual Approach" observed in the subsequent developmental stage among larval Ambystoma opacum, Ambystoma tigrinum, and Ambystoma maculatum. 


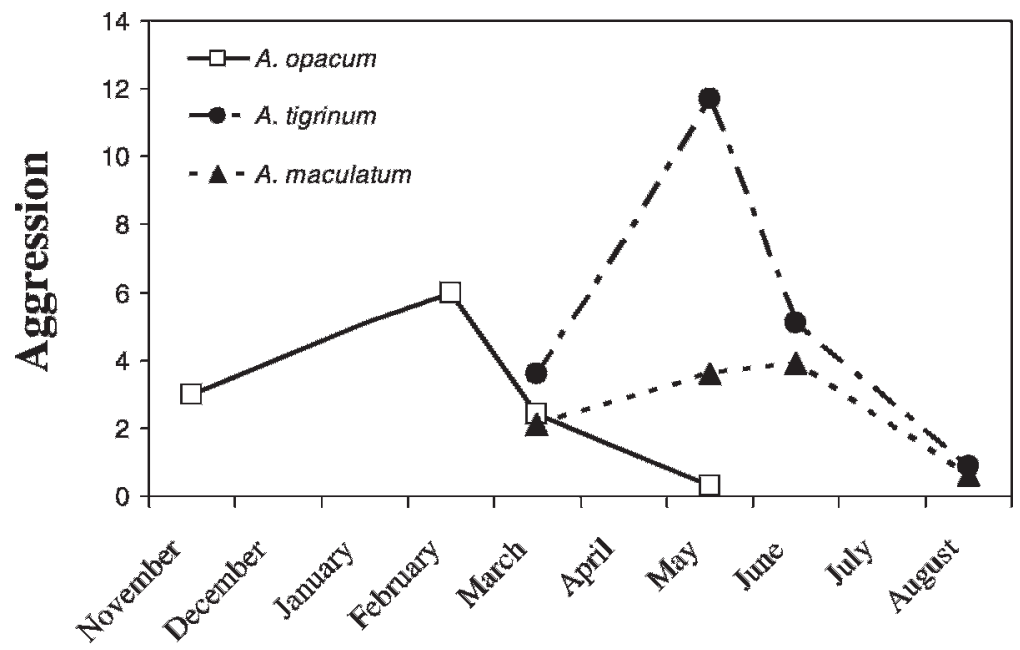

FIG. 4. Projected in situ aggression (combined totals of the behaviors "Move Toward," "Lunge," "Bite," "Predation," and "Mutual Approach" / 30-min trial) among larval Ambystoma opacum, Ambystoma tigrinum, and Ambystoma maculatum in southern Illinois. The dates at which larvae enter each developmental stage were determined from digital photographs of larvae taken from ponds in the Shawnee National Forest between November 2005 and May 2007 (CLM, unpubl. data).

A. opacum on later-hatching species is less likely than if these species emerged earlier. Therefore, lower rates of $A$. opacum aggression when cohabiting with $A$. tigrinum and $A$. maculatum may represent one mechanism through which coexistence is facilitated. Conversely, as $A$. maculatum are present when $A$. tigrinum become most aggressive (Fig. 4), relatively high rates of predation by A. tigrinum would be expected, and this strategy may contribute to the observed high growth rate of the latter, as is seen in cannibalistic A. tigrinum, Ambystoma jeffersonianum, and A. opacum in a previous study (Brodman, 2004). However, in addition to developmental stage, relative size between larvae contributes to aggressive interactions, as larger $A$. opacum and $A$. tigrinum prey on smaller $A$. maculatum even when the larger species are at less aggressive developmental stages (CLM, unpubl. data.) Consequently, future studies should examine changes in the prevalence of predation within larval communities through ontogeny in the context of both aggression levels and size variation.

Species-specific aggression rates observed in this study support previous conclusions regarding the importance of morphology and growth to agonistic behavior. Wider heads and faster growth rates in A. tigrinum compared to sympatric species (Keen et al., 1984) confer a predatory advantage that agrees with our observations of $A$. tigrinum as a superior aggressor. Ambystoma maculatum, which is typically the smallest of the three species in ponds, have been hypothesized to coexist with larger Ambystoma species by using refugia and, thus, decreasing the potential of encountering predators (Brodman, 1996; Brodman and Jaskula, 2002); such behavioral strategies, in conjunction with the relatively low levels of aggression displayed in our study, would reduce aggressive encounters with conspecifics and other larval Ambystoma.

Despite species differences in aggression, the overall similarities in ontogenetic patterns of aggression among multiple species in our study suggest that changes in aggression are associated with aspects of development shared by Ambystoma larvae. Factors such as limb development and their associated changes in frequency and mode of locomotion (Anderson, 1968) may impact aggression by influencing contact rates among larvae. Anderson (1968) observed that Ambystoma larvae swam very little prior to development of rear legs; larvae in our experiments exhibited similar behavior, and we hypothesize that reduced movement early in the larval period results in relatively few aggressive interactions. Among metamorphic larvae, the reduced aggression observed in our study may be associated with dramatic development of the jaw and limbs occurring at metamorphosis (Duellman and Trueb, 1986), because these changes contribute to decreased feeding behavior (Relyea and Yurewicz, 2002) and could reduce frequency of contact between larvae. Metamorphic larvae used in our study would commonly float on the water's surface, remaining motionless for the duration of the trial.

The absence of winner or loser effects in this study contrasts with previous findings that an 
act of predation increases subsequent aggression rates (Brodman, 2004). Because larvae in this study were paired for equal size, we effectively eliminated size advantages between larvae, and consequently, no acts of predation were recorded. That we did not observe winner or loser effects in the absence of predation supports Brodman's (2004) hypothesis that predation itself and the associated increases in growth and population size variation are responsible for increases in aggression following predation.

Given that all focal species exhibited a similar behavioral pattern through ontogeny, we hypothesize that external factors, such as larval density and size variation, operate on these intrinsic ontogenetic patterns of aggression. Future studies of ontogenetic behavioral changes should examine the interplay between ontogeny and external factors, such as larval density, relative size, and food limitation. By examining pond species composition during developmental stages when larvae are most aggressive, we may identify the periods of highest predation risk and those species that are most at risk as well as determine how predation among species may ultimately influence species distributions. Furthermore, additional trials consisting of interspecific comparisons are necessary to determine whether ontogenetic patterns of aggression occur in similar fashion among intra- and interspecific larval pairs.

Acknowledgments.-We thank T. Bommarito, E. Croteau, L. Kjaer, M. Steffen, and M. Venarsky for assistance in egg collection and care of larvae, K. Regester for data on pond localities and species compositions, and the Touch of Nature Environmental Center and U.S. Forest Service for allowing us to collect egg masses. We also thank J. D. Reeve and E. M. Schauber for statistical advice and C. M. Lehman and the anonymous reviewers for providing useful comments on a previous version of this manuscript. This research was funded by a Delyte and Dorothy Morris Doctoral Fellowship awarded to CLM, and all aspects of this research were conducted in accordance with Southern Illinois University IACUC Protocol 05037 and Illinois Department of Natural Resources Collection Permit A07-4048.

\section{Literature Cited}

Abramoff, M. G., P. J. Magalhaes, and S. Ram. 2004. Image processing with ImageJ. Biophotonics $11: 36-42$

ANDERSON, J. D. 1968. A comparison of the food habits of Ambystoma macrodactylum sigillatum, Ambystoma macrodactylum croceum, and Ambystoma tigrinum californiense. Herpetologica 24:273-284.
Blaustein, A. R., and R. K. O'Hara. 1986. An investigation of kin recognition in Red-Legged Frog (Rana aurora) tadpoles. Journal of Zoology 209:347-343.

Boone, M. D., D. E. Scott, And P. H. Niewarowski. 2002. Effects of hatching time for larval ambystomatid salamanders. Copeia 2002:511-517.

Branch, L. C., AND R. Altig. 1981. Nocturnal stratification of three species of Ambystoma larvae. Copeia 1981:870-873.

BRIDGES, C. M. 1999. Predator-prey interactions between two amphibian species: effects of insecticide exposure. Aquatic Ecology 33:205-211.

Brodman, B. 1996. Effects of intraguild interactions on fitness and microhabitat use of larval Ambystoma salamanders. Journal of Herpetology 29:111-113.

- 2 2004. Intraguild predation on congeners affects size, aggression, and survival among Ambystoma salamander larvae. Journal of Herpetology 38:21-26.

Brodman, B., AND J. Jaskula. 2002. Activity and microhabitat use during interactions among five species of pond-breeding salamander larvae. Herpetologica 58:346-354.

BrunKow, P. E., AND J. P. Collins. 1996. Effects of individual variation in size on growth and development of larval salamanders. Ecology 77:1483-1492.

Duellman, W. E., AND L. TRueb. 1986. Biology of Amphibians. McGraw-Hill Inc., New York.

Hansson, L. A., A. Nicolle, J. Broderson, P. Romare, P. A. Nilsson, and C. Bronmark. 2007. Consequences of fish predation, migration, and juvenile ontogeny on zooplankton spring dynamics. Limnology and Oceanography 52:696-706.

Hassinger, D. D., J. D. Anderson, and G. H. Dalrymple. 1970. The early life history and ecology of Ambystoma tigrinum and Ambystoma opacum in New Jersey. American Midland Naturalist 84:474-495.

Horne, M. T., And W. A. Dunson. 1995. Effects of low $\mathrm{pH}$, metals, and water hardness on larval amphibians. Archives of Environmental Contamination and Toxicology 29:500-505.

Keen, W. H., J. Travis, and J. Juilianna. 1984. Larval growth in three sympatric Ambystoma salamander species: species differences and the effects of temperature. Canadian Journal of Zoology 62:1043-1047.

LANDAU, H. G. 1951a. On dominance relations and the structure of animal societies: I. Effects of inherent characteristics. Bulletin of Mathematical Biophysics 13:1-19.

—_. 1951b. On dominance relations and the structure of animal societies: II. Some effects of possible social causes. Bulletin of Mathematical Biophysics 13:245-262.

LefF, L. G., AND M. G. Bachmann. 1986. Ontogenetic changes in predatory behavior of larval Tiger Salamanders (Ambystoma tigrinum). Canadian Journal of Zoology 64:1337-1344.

Mathis, A., K. L. Murray, and C. R. Hickman. 2003. Do experience and body size play a role in responses of larval Ringed Salamanders, Ambystoma annulatum, to predator kairomones? Laboratory and field assays. Ethology 109:159-170. 
Petranka, J. W. 1998. Salamanders of the United States and Canada. Smithsonian Institute Press, Washington, DC.

Polis, G. A., C. A. Myers, and R. D. Holt. 1989. The ecology and evolution of intraguild predation: potential competitors that eat each other. Annual Review of Ecology and Systematics 20:297-330.

POWERS, J. H. 1907. Morphological variation and its causes in Ambystoma tigrinum. Studies of the University of Nebraska 7:197-274.

Regester, K. R., K. R. LiPS, AND M. R. Whiles. 2006. Energy flow and subsidies associated with the complex life cycle of ambystomatid salamanders in ponds and adjacent forest in southern Illinois. Oecologia 147:303-314.

Reilly, S. M., G. V. Lauder, and J. P. Collins. 1992. Performance consequences of a trophic polymorphism in typical and cannibal phenotypes of Ambystoma tigrinum. Copeia 1992:672-679.

RelyeA, R. A., AND K. L. Yurewicz. 2002. Predicting community outcomes from pairwise interactions: integrating density- and trait-mediated effects. Oecologia 131:569-579.

Semlitsch, R. D., and S. B. Reichling. 1989. Densitydependent injury in larval salamanders. Oecologia 81:100-103.

SMITH, C. K. 1990. Effects of variation in body size on intraspecific competition among larval salamanders. Ecology 71:1777-1788.

SRedL, M. J., AND J. P. Collins. 1992. The interaction of predation, competition, and habitat complexity in structuring an amphibian community. Copeia 1992:607-614.
Stenhouse, S. L. 1985. Interdemic variation in predation on salamander larvae. Ecology 66:1706-1717.

Stenhouse, S. L., N. G. Hairston, And A. E. Cobey. 1983. Predation and competition in Ambystoma larvae: field and laboratory experiments. Journal of Herpetology 17:210-220.

Walls, S. C. 1995. Differential vulnerability to predation and refuge use in competing larval salamanders. Oecologia 101:86-93.

- 1998. Density dependence in a larval salamander: the effects of interference and food limitation. Copeia 1998:926-935.

Walls, S. C., AND R. G. Jaeger. 1987. Aggression and exploitation as mechanisms of competition in larval salamanders. Canadian Journal of Zoology 65:2938-2944.

Walls, S. C., AND R. D. Semlitsch. 1991. Visual and movement displays function as agonistic behavior in larval salamanders. Copeia 1991:936-942.

Walls, S. C., AND M. G. Williams. 2001. The effect of community composition on persistence of prey with their predators in an assemblage of pondbreeding amphibians. Oecologia 128:134-141.

Wildy, E. L., D. P. Chivers, J. M. Kiesecker, AND A. R. Blaustein. 2001. The effects of food level and conspecific density on biting and cannibalism in larval Long-Toed Salamanders, Ambystoma macrodactylum. Oecologia 128:202-209.

Wissinger, S. A. 1989. Seasonal variation in the intensity of competition and predation among dragonfly larvae. Ecology 70:1017-1027.

Accepted: 9 December 2008. 